\title{
Stress urinary incontinence: A case-based discussion
}

\author{
Lesley Carr, MD, FRCSC; ${ }^{*}$ Jacques Corcos, MD, FRCSC ${ }^{\dagger}$
}

*Associate Professor, University of Toronto, Department of Surgery, Division of Urology, Sunnybrook Health Sciences Centre, Toronto, ON; 'Professor of Surgery (Urology), McGill University, Montreal, QC

Cite as: Can Urol Assoc J 2012;6(5):S125-6. http://dx.doi.org/10.5489/cuaj.12234

\section{Abstract}

At the conclusion of the sessions on stress urinary incontinence (SUI) in women, participants at the 2012 Canadian Urology Forum (academic and clinical urologists from across Canada) engaged in a discussion of optimal SUI evaluation and management. The discussion was led by Dr. Lesley Carr and co-facilitated by the other members of the Forum's steering committee and was based on a patient case. This review provides a summary of the case and the discussion it generated.

\section{Case study: Background}

The patient is a 44-year-old woman with two children. She initially presented at age 41, complaining of stress urinary incontinence (SUI) with coughing and exercise. At that time, she was wearing pantiliners on a daily basis for protection against frequent incontinent episodes.

Examination at that time showed moderate hypermobility, with no significant prolapse. Urinalysis was negative, post-void residual (PVR) was small, and the stress test was positive. She had no other remarkable medical history.

She subsequently underwent insertion of a tension-free transvaginal tape by transobturator route (TVT-O). There were no perioperative or postoperative complications and the recovery was uneventful.

\section{Case study: Presentation}

The patient returns three years after the TVT-O. She reports that she considered the operation to be very successful and that she did not have any symptoms of SUI for about one year postoperatively. However, the current situation is once again suboptimal.

She is now 44 years old and her overall health continues to be good. However, she is once again experiencing SUI with exercise and coughing. The frequency is approximately every two hours during the day and averages twice nightly. This is having a con- siderable deleterious impact on her quality of life, as she is very active in sports and again has to wear pantiliners most of the time for protection and maxi pads during exercise.

\section{Evaluation}

The physical examination shows no prolapse, minimal hypermobility and no erosion. During your discussion, she indicates that she believes that stress incontinence is the main component. The PVR is $30 \mathrm{cc}$.

\section{Discussion}

The participants were asked a series of questions regarding this case and offered a variety of multiple-choice answers. The first question asked whether the participants would order cystoscopy, multichannel urodynamics, both tests or neither test. Eighty per cent of the participants elected to choose both tests, while $8 \%$ chose cystoscopy alone. Twelve per cent indicated they would choose neither test.

When the participants were asked if they would recommend a trial of anticholinergic therapy at this point, $88 \%$ said they would and $12 \%$ indicated they would not. During the ensuing discussion, the participants discussed the fact that there is very little downside to trying anticholinergics at this point, but acknowledged that very few patients will be satisfied with this intervention alone.

In the event that the anticholinergic does not improve her symptoms, the participants were asked which intervention they would then recommend. More than half (56\%) selected a repeat midurethral sling (MUS) (inserted retropubically), 22\% indicated they would recommend a bulking agent, 13\% opted for a repeat MUS (transobturator insertion), and 9\% selected a pubovaginal bladder neck sling. None of the participants selected a retropubic suspension (e.g., Burch).

The discussion then turned to the medico-legal status of vaginal mesh surgeries that has arisen in the United States following warnings against using mesh to repair pelvic organ prolapse (POP). The warning states that for POP repair, transvaginal placement of mesh may expose patients to greater risk than other options. Although there is no such warning for the use of mesh for traditional MUS, 
the participants agreed that many patients are aware of the FDA warning and ask for more information or even cancel scheduled insertion of a MUS. Many participants indicated that they have changed the way they counsel their patients preoperatively to proactively make a distinction between POP and MUS and dispel any concerns the patient may have about this safe and well-studied intervention.
Competing interests: Dr. Corcos is an ongoing paid consultant with Astellas Canada. He and Dr. Carr have received speaker fees, educational grants and/or travel assistance from Astellas Canada within the last two years.

Correspondence: Dr. Lesley K. Carr, Division of Urology, Room MG501, Sunnybrook Health Sciences Centre, 2075 Bayview Ave, Toronto, ON M4N 3M5; fax: 416-480-5116; lesley.carr@sunnybrook.ca; Dr. Jacques Corcos, Hôpital Général Juif - Sir Mortimer B. Davis Urologie E-944, 3755 Ch De La CôteSainte-Catherine, Montreal, QC H3T 1E2; icorcos@uro.jgh.mcgill.ca 